\section{P1-208 EPIDEMIOLOGY INTO ACTION: SURVEILLANCE OF DEATHS AND MONITORING OUALITY OF PERINATAL HEALTHCARE TO REDUCE MATERNAL AND INFANT MORTALITY IN BELO HORIZONTE CITY, BRAZIL}

doi:10.1136/jech.2011.142976e.1

S Lansky, ${ }^{*}$ R D Perillo, G Maciel, S Castro, N G Madeira. Belo Horizonte Health Department, Belo Horizonte, Minas Gerais, Brazil

Since 1999 a perinatal health commission was set in Belo Horizonte to establish a policy framework to reduce maternal and infant mortality. A comprehensive audit of maternity care was made and in 2000 an integrated system was organised, from prenatal to birth care and the continuum of care after maternity discharge. Nine hospitals providing inadequate care were closed, in a total of 16 maternity-hospitals public services. Surveillance of maternal deaths (since 1997) and infant and perinatal (since 2002) process audit feedback the staff in order to avoid other preventable deaths. Hospital and health clinics charts are evaluated and family interviews provide information about the circumstances of maternal and infant deaths. Since 2006 an observational system to monitor quality of care process was established within the maternities: auditors evaluate hospital charts and interview $5 \%$ of all women in labour and women after birth. Important changes were registered: in 1999 , only $20 \%$ of women in labour were monitored with partography, whereas in $2006,80 \%$ had an adequate or complete partograph. Infant mortality was reduced by $65 \%$ and maternal mortality by $25 \%$ between 1994 and 2009 . There was a 3.1 reduction in the risk of death of intrapartum causes, one of the most prevalent and preventable causes of infant deaths: in 1999, 9.9 perinatal deaths/ 1000 births (birthweight $\geq 1500 \mathrm{~g}$ ) occurred, of which $4.2 / 1000$ births were from intrapartum causes, whereas in 20074.2 perinatal deaths/1000 births occurred, of which 1.3/1000 births were from intrapartum causes.

\section{P1-209 TEACHING FACTORS ASSOCIATED TO VOICE DISORDERS: A CASE-CONTROL STUDY}

doi:10.1136/jech.2011.142976e.2

${ }^{1,2}$ S Giannini, 'M do R Latorre, ${ }^{1}$ L Ferreira. ' School of Public Health USP, São Paulo, Brazil; ${ }^{2}$ Pontifical Catholic University of São Paulo, São Paulo, Brazil

Introduction and Aims of the Study Teachers constitute professional category with high occurrence of voice disorders due to this occupation's intense vocal demand and to unfavourable work environments. To identify job's factors associated to voice disorders in teachers of the public school of the city of São Paulo.

Methods This is matched case-control study. The case group was teachers with vocal quality deviations and vocal fold lesion or altered larynx. The control group was selected at the same schools in which the case group individuals worked. Both groups answered the questionnaires: Conditions of Vocal Production-Teacher(CVP-T), Vocal Handicap Index (VHI), Job Stress Scale (JSS) and Work Ability Index (WAI). The analysis was done using qui-squared association test and multiple regression models.

Results $78.8 \%$ of the control group are concentrated in lower levels of demand of job stress, while $69.3 \%$ of the case group are located at higher levels $(p=0.019)$. Regarding work control, $63.1 \%$ of the control group had higher levels of control, while $73.1 \%$ of the case group are in the lower categories $(p=0.034)$. There is a significant association between low work ability and voice disorder $(p<0.001)$. This association is maintained in the multivariate analysis, where low $(\mathrm{OR}=9.5, \mathrm{p}=0.001)$ and moderate $(\mathrm{OR}=6.7, \mathrm{p}<0.001)$ capacity for work were also associated with voice disorder.
Conclusions Low and moderate ability to work show high correlation with the presence of voice disorder. The presence of voice disorder may jeopardise their careers because these professionals depend essentially on their voices to teach.

\section{P1-210 INCOME INEQUALITY AND CAUSE-SPECIFIC MORTALITY DURING ECONOMIC DEVELOPMENT}

doi:10.1136/jech.2011.142976e.3

E W Lau, K Y Tin, G M Leung, M C Schooling.* The University of Hong Kong, Hong Kong, China

Introduction Life expectancy is strongly related to national income, whether there is an additional contribution of income inequality is unclear. We examined the association of income inequality with mortality over historic time in a non-western population which has experienced uniquely rapid economic development.

Methods We used negative binomial regression to examine the association of neighbourhood level Gini, adjusted for age, sex and income, with all-cause and cause specific mortality rates in Hong Kong for an earlier (1976, 1981 and 1986) and later (1991, 1995, 2001 and 2006) period.

Results Neighbourhood Gini was not associated with all-cause mortality in the earlier period (incident rate ratio (IRR) $0.96,95 \% \mathrm{CI}$ 0.93 to 1.00 per 0.1 change in Gini) but was in the later period (IRR 1.25 , 95\% CI 1.20 to 1.29), adjusted for age, sex and absolute income, despite a consistent association with non-medical mortality in both periods (IRR 1.11, 95\% CI 1.06 to 1.17 and 1.29, 1.21 to 1.37). In the later period Gini was associated with mortality from cardiovascular diseases, including ischaemic heart disease (IHD), and respiratory diseases, but not with mortality from cancer.

Conclusion The impact of income inequality on cardio-respiratory mortality emerged over a period of economic development. Whether there is any additional benefit beyond those provided by material conditions from re-distributing income is unclear and may be confined to some specific causes of death, such as non-medical mortality and IHD, for which specific interventions could be designed.

\section{P1-211 NEIGHBOURHOOD SOCIODEMOGRAPHIC, PHYSICAL, SERVICE-RELATED, AND SOCIAL-INTERACTIONAL CHARACTERISTICS AND BMI OR WAIST CIRCUMFERENCE IN THE RECORD STUDY: EVALUATION OF THE SEPARABILITY OF ASSOCIATIONS WITH A NEIGHBOURHOOD CHARACTERISTIC-MATCHING TECHNIQUE}

doi:10.1136/jech.2011.142976e.4

${ }^{1,2} \mathrm{C}$ Leal, ${ }^{*} \mathrm{~K}$ Bean, ${ }^{1} \mathrm{~B}$ Chaix. ${ }^{1}$ Inserm U707, Paris, France; ${ }^{2}$ EHESP, Paris, France; ${ }^{3}$ IPC Center, Paris, France

Introduction Previous studies on the environment and obesity have estimated mutually adjusted effects of different environment factors that are strongly correlated with each other, without carefully assessing whether it is possible to disentangle these effects.

Methods We investigated whether correlated neighbourhood characteristics related to the sociodemographic, physical, service-related, and social-interactional environments measured within ego-centered areas were associated with BMI and waist circumference, and assessed whether or not these associations could be disentangled using an original neighbourhood characteristic-matching technique (analysis of each environmental effect within pairs of individuals similarly exposed to another environmental variable). We conducted cross-sectional analyses of 7230 adults from the RECORD Cohort Study (Paris region, France). 